\title{
Desafios contemporâneos para a formação de jovens e adultos
}

\section{Contemporary challenges for the education of young people and adults}

\author{
Ana Maria Costa e Silva*
}

\begin{abstract}
RESUMO
As últimas quatro décadas têm sido progressivamente marcadas por uma atenção e investimento na formação, nomeadamente de jovens e adultos, particularmente a partir da década de noventa do século passado, com o acentuado e persistente discurso da importância da formação-aprendizagem ao longo da vida. Partindo desta constatação, discutiremos neste artigo alguns dos pressupostos subjacentes aos discursos da formação e da aprendizagem ao longo da vida. Procuramos evidenciar fragilidades e controvérsias que têm estado presentes, tanto nos discursos como nas práticas, e identificar alguns desafios que se colocam ao campo da formação, reconhecendo, tal como Pineau (2004), que os tempos formadores são demasiadamente importantes para serem apenas os das formações instituídas. Assim, procuraremos desocultar e reabilitar o ponto de vista do adulto que se forma e pensar sobre a dinâmica de formatividade que não se esgota no âmbito da institucionalização da formação. Incidiremos a nossa análise e reflexão na importância da interação entre percursos de formação e trajetórias de vida, evidenciando a relevância da experiência na aprendizagem dos adultos e na construção de saberes. Esta análise permite-nos, também, salientar a importância e necessidade dos contextos de formação (formais e não formais)
\end{abstract}

* A autora é doutorada em Educação, na área de especialização de Desenvolvimento Curricular, professora e investigadora na Universidade do Minho e tem, ao longo da última década, centrado os interesses de investigação nas questões relativas à formação de adultos e identidades socioprofissionais e lecionado, em cursos de graduação e pós-graduação unidades curriculares associadas a esta temática.

Toda a correspondência relativa a este artigo deverá ser enviada para: Ana Maria Costa e Silva, Instituto de Educação e Psicologia, Universidade do Minho, Campus de Gualtar, 4710-057 Braga - Portugal.

E-mail: anasilva@iep.uminho.pt. 
tomarem em consideração a autoria dos sujeitos da/em formação, dimensão fundamental para o seu (auto)reconhecimento social e para a (re)construção de identidades.

Palavras-chave: formação; aprendizagem; experiência(s); construção de saberes; identidade(s).

\begin{abstract}
The last four decades have been progressively marked by a focus and investment on training, namely for young people and adults, particularly from the 90s of the last century onwards, together with the emphatic and persistent discourse on the importance of lifelong learning-education. From this viewpoint, we will discuss in this article some of the presumptions underlying the discourses on lifelong education and learning. We will try to point out frailties and controversies that have been present, both in the discourses and the practices, and identify some challenges that are posed on the field of training, acknowledging, like Pineau (2004), that the educating moments are too important to be left just to institutionalized education. Thus, we will try to unveil and rehabilitate the point of view of the adult that is being educated and think about the dynamic of the training process that does not limit itself to the sphere of the institutionalization of education. Our analysis and reflexion will focus on the importance of the interaction between training courses and life trajectories, pointing out the relevance of experience in adult learning and in the construction of knowledges. This analysis allows us, as well, to point out the importance and need that the training contexts (both formal and informal) take into consideration the authorship of the individuals involved in/undergoing training, being this a fundamental dimension to their social (self) acknowledgment and (re)construction of identities. Key-words: education; learning; experience(s); construction of knowledges; identity(ies).
\end{abstract}

\title{
Introdução
}

As reflexões que aqui iremos partilhar em torno da formação de jovens e adultos e, mais especificamente, sobre os desafios que hoje se lhe colocam e se nos colocam, têm subjacentes algumas questões, nomeadamente: i) o que se deve ensinar?; ii) o que se deve aprender?; iii) que tipo de 
pessoas queremos formar e desenvolver?; iv) que tipo de sociedade queremos construir?

Sendo já indiscutível que nos encontramos num tempo social e profissionalmente dominado pela necessidade e cadência da intervenção formativa nos mais diversificados domínios: temporais - formação ao longo de toda a vida - e contextuais - formação em múltiplos campos sociais, organizacionais e profissionais, devemos perguntar: quais os desafios que se nos levantam ao pensarmos e intervirmos neste campo?

Identificaremos dois aspectos prévios, do nosso ponto de vista importantes, para podermos perceber algumas características essenciais - da sociedade atual e dos indivíduos que a integram - e situarmo-nos face aos novos reptos que consideramos fundamentais.

Em primeiro lugar, salientamos o fato de ser importante tomar em conta que, para pensarmos hoje o campo da formação, nomeadamente da formação de jovens e adultos, devemos reconhecer um conjunto de aspectos que nos últimos 40 anos se alteraram significativamente nos níveis político, social, econômico e cultural, provocando novos modos de pensar a inserção e o desenvolvimento pessoal e social, o trabalho, o emprego e a profissão, com conseqüências na forma como se organiza e vive a formação e a relação que com ela estabelecem os indivíduos.

A democratização da educação, a acelerada transformação dos processos produtivos e a própria concepção do trabalho que se foi alterando, tornando mais tênue a ligação entre trabalho e emprego, são aspectos que têm clara repercussão no incentivo à formação e na sua concomitância com os contextos sociais e de trabalho em que participam os sujeitos (SANTOS, 1989; DUBAR e TRIPIER, 1998).

A mudança do sentido dos trajetos de mobilidade profissional (que deixou de ser linear e progressivo) e o claro incentivo ao desenvolvimento de estratégias individualizadas para assegurar e melhorar a própria empregabilidade são determinantes nesta mudança das relações entre formação, trabalho e desenvolvimento individual e social. São disto um claro exemplo o apelo da União Européia em 1996 para a "Aprendizagem ao Longo da Vida", evidenciando a necessidade de comprometer os próprios indivíduos (e não exclusivamente, nem tanto as instituições de trabalho e de formação) no seu investimento na formação no sentido de os tornar empregáveis, mantendo-os "em estado de competência e de competitividade no mercado" (DUBAR, 2000, p. 112).

Outro aspecto a ter em atenção prende-se com a condição de jovem e adulto na atualidade. De salientar que os cenários atuais constituem situa- 
ções complexas a diferentes níveis com as quais o jovem e adulto têm de confrontar-se, (re)inventando estratégias adequadas ou, pelo menos, adaptadas a esses contextos. São claras as metamorfoses, tanto no nível do ciclo de vida e da definição da idade adulta como no nível cognitivo, sendo freqüente a necessidade de reorientação de aprendizagens anteriores.

Hoje em dia, o jovem e o adulto vivenciam um sentimento identitário instável, com freqüentes perdas e/ou (re)orientações identitárias, nos níveis social, profissional, afetivo, entre outros. Encontram-se perante a necessidade de uma pluralidade de opções, e até de trajetórias, cuja cadência é muitas vezes desorganizada e imprevisível. A seqüencialidade e linearidade dos ciclos de vida, acompanhados de rituais de passagem, sucumbiram face à sua segmentação temporal e espacial. Os espaços profissionais, familiares, associativos e de lazer encontram-se, freqüentemente, interpenetrados uns pelos outros, e os tempos previstos para o casamento, para o início da vida ativa e para a reforma encontram-se desabitados, podendo, em qualquer idade, virem a ser ocupados. De acordo com Boutinet (1998, p. 166), "as passagens socialmente ou mesmo ritualmente organizadas, dão lugar às passagens existenciais debilmente socializadas"; assim, o adulto é frequentemente confrontado com transições, mudanças de percurso de vida e, muitas vezes, mesmo rupturas nos projetos existenciais.

Embora as transições nas trajetórias, e até as crises existenciais e de desenvolvimento, possam ser lidas e apropriadas como "oportunidades para [a pessoa] se desenvolver concedidas pela vida na seqüência da maturação de fatores biológicos, socioculturais e psíquicos [...], oportunidade de formação experiencial (entendida pela e através da experiência da vida adulta), e de uma transformação experiencial" (HOUDE, 1989, p. 146-147), também não devemos esquecer que estas transições e o modo como são experienciadas dependem de algumas condições. Houde (1989) identifica vários fatores intervenientes no modo como elas são apropriadas, nomeadamente: i) o momento: início da carreira, meio da vida ou próximo da reforma; ii) o espaço: familiar, profissional, associativo; iii) o ritmo da transição e os meios utilizados. Estes fatores intervêm no modo de viver as crises desenvolvimentais, bem como nos processos de transformação e individualização.

Nas transições com as quais o jovem e o adulto convivem tem particular impacto a variável da sua antecipação ou não, pois uma transição antecipada é algo previsto (BOUTINET, 1998). Quando não desejada, mas pelo menos aceite, a antecipação poderá desencadear mecanismos de prevenção, de evitamento, de procura de estratégias alternativas. Por outro lado, quando a antecipação se inscreve no registro do desejo, desenvolve 
mecanismos de previsão, de idealização e de projeto que facilitam a concretização do futuro desejado.

As alterações emergentes e progressivas ao longo das últimas décadas nos macrocontextos políticos, econômicos e sociais, em articulação com a condição de jovem e adulto na atualidade, constituem dois fatores relevantes para a acentuada procura e oferta da formação, devendo ser considerados no modo como devemos (re)pensar a formação de jovens e adultos, nomeadamente no nível do(s) conhecimento(s) e do(s) conteúdo(s) a mobilizar e/ou considerar nos espaços-tempos de formação e das modalidades/metodologias privilegiadas, aspectos em que incidiremos mais detalhadamente, pois sobre eles recaem alguns dos desafios contemporâneos essenciais para o campo da formação.

\section{Conhecimento(s), experiência(s) e autoria(s)}

Os dois aspectos que anteriormente identificamos encontram eco nas questões em que agora procuramos incidir, nomeadamente nos distintos modos de valorização, incidência e apropriação do(s) conhecimento(s) e da(s) experiência(s).

Ao cenário marcadamente instável e competitivo, em que as trajetórias de vida e profissionais dos indivíduos se constroem, acrescem os discursos e as motivações sociopolíticas para a formação, sendo constantemente atualizadas pelos novos desafios da sociedade contemporânea que é, freqüentemente, denominada como "sociedade da informação", "sociedade do conhecimento" e/ou "sociedade da aprendizagem", emergindo como questões relevantes as da formação, da aprendizagem e do estatuto do conhecimento. É sobre este último que iremos centrar-nos mais particularmente para dar conta de diferentes relações e estatutos que têm sido assumidos, com repercussões nos modos de formar e aprender.

Ao longo das últimas décadas, na seqüência da transformação das relações laborais e sociais, tem sido desenvolvido um conjunto de políticas que interferem diretamente no estatuto atribuído ao saber, nomeadamente no campo da formação de jovens e adultos. Salientamos alguns desses estatutos, que apesar de poderem coexistir atualmente, são mais ou menos predominantes em determinados períodos históricos. 
Até meados da década de 70 , os sujeitos estabeleciam uma relação relativamente estável com o saber, que constituía a sua "bagagem" cognitiva para aceder ao mundo do trabalho e possuir uma qualificação pessoal e social. Este saber universal, objetivo e cumulativo, referenciado nos critérios de cientificidade e privilegiando uma explicação causal dos fenômenos e acontecimentos (USHER e BRYANT, 1992), permite não só explicar retrospectivamente, como predizer prospectivamente acontecimentos e fenômenos (ANDERSON e COLBS, 1986), identificando-se com uma concepção fundamentalmente instrumentalista do conhecimento e da relação da teoria com a prática (SANTOS, 1988; USHER e BRYANT, 1992).

Este estatuto do conhecimento coexist(e)ia com os sistemas de produção e de trabalho taylorizados e relativamente estáveis, pressupondo funções estritamente delimitadas e intervenções antecipadamente definidas.

A alteração progressiva deste modelo de trabalho mais visível a partir da década de 80 , a par das sucessivas e freqüentes alterações e mudanças, tanto nos meios estritamente produtivos e de trabalho como nos contextos sociais mais amplos, e a própria precarização do emprego e do trabalho, contribuíram para a emergência de novos discursos, nomeadamente os da passagem da qualificação à competência: nos novos contextos já não basta ter-se uma qualificação, mas importa ser competente de modo a garantir a própria empregabilidade.

Com o aparecimento dos discursos sobre as competências e a empregabilidade, mais intensamente a partir da década de 90 , o estatuto do "saber bagagem" fragilizou-se; passou-se da noção do saber como patrimônio cognitivo universal para a noção de um saber contextualizado, descartável e permanentemente atualizável e substituível através de sistemas de formação contínua. É menos relevante o saber universal, para se incidir nas dimensões locais e contextuais emergentes nas comunidades sociais e organizacionais, cujas características, para além de singulares, são particularmente permeáveis a alterações sistemáticas. O conhecimento é fundamentalmente indutivo e emergente dos contextos e dos sujeitos concretos; menos teórico e mais experiencial.

Mais recentemente, tem-se vindo a valorizar não apenas o saber, universal ou contextualizado e fundamentalmente exterior aos sujeitos, mas também e com progressiva relevância, os sujeitos produtores e construtores de saber.

Assim, podemos perceber que as figuras do "saber bagagem" e do "saber descartável" coexistem com uma outra concepção do saber e da sua relação com o mundo, isto é, com a figura do "saber inter e intra subjetivo" 
que tem emergido em diferentes dispositivos de formação, como salientaremos mais à frente.

Neste último caso, o saber não é tanto um intermediário da relação dos sujeitos com o mundo que lhes é exterior, mas é um mediador, que, sendo pertinente para a produção dos sujeitos e dos seus mundos, transforma tanto os sujeitos como esses mundos.

Neste caso, o sujeito adquire a centralidade no processo de aprendizagem, cabendo-lhe, por um lado, a atribuição de sentido a uma realidade complexa, atribuição à qual não é alheia a sua história cognitiva, afetiva e social (BARTH, 1996) e, por outro lado, a sua mobilização para autoproduzir a sua vida (PINEAU, 1983), utilizando a si próprio como recurso no processo de formação-aprendizagem (CHARLOT, 1997).

O processo narrativo e reflexivo, inter e intra subjetivo, é essencial para a criação de sentido e construção de conhecimento, na medida em que possibilita um reconhecimento de autoria à experiência, tematizando-a e organizando-a espaçotemporalmente, gerando uma consciência metacognitiva. Considerar as narrativas nos processos de formação, nomeadamente de jovens e adultos, é autorizar(-se) a construir o sentido e o significado do(s) saber(es) para se reconhecer como sujeito autor do seu processo de desenvolvimento e produtor de conhecimentos emergentes $\mathrm{da}(\mathrm{s})$ experiência(s).

Este processo de relação com o saber, ao mesmo tempo que proporciona aos sujeitos em formação reconhecerem-se na sua autoria de construtores de saberes, implica que, de alguma forma, nos espaços-tempos de formação, nos centremos mais no jovem e adulto em formação que na estrita formação de jovens e adultos (SILVA, 2000).

Neste pressuposto, o conhecimento e os critérios de cientificidade já não se definem tanto por uma racionalidade cognitiva e pela conformidade aos modelos pré-estabelecidos, nem mesmo por uma racionalidade instrumental na qual estão presentes os critérios de eficiência técnica, mas procura integrar uma racionalidade reflexiva e comunicacional que tem vindo a evidenciar-se como essencial à apropriação e intervenção em contextos complexos, organizacionais e sociais, como a grande maioria dos que caracterizam a sociedade contemporânea.

A intervenção e gestão no/do incerto e do aleatório nos contextos sociais e de trabalho, implica a capacidade de interpretação das peripécias e acontecimentos, utilizando-os como ocasiões de aprendizagem e de enriquecimento do repertório de ações eficazes (VELTZ e ZARIFIAN, 1993; SILVA, 2004), implicando que, mais do que a aplicação de conhecimentos 
produzidos em contextos científico-epistemológicos, se reinventem modos ajustados às situações complexas de intervenção social. Esses saberes constituem-se, freqüentemente, através da ativação de estratégias comunicacionais e intersubjetivas (HABERMAS, 1987; SILVA, 2007) que, para além de constituírem uma alternativa à objetividade, reportam igualmente uma qualidade nova ao conhecimento, a qual é aferida pela "satisfação pessoal que dá a quem a ele acede e o partilha. (...) Assim ressubjetivado, o conhecimento científico ensina a viver e traduz-se num saber prático" (SANTOS, 1988, p. 54-55).

\section{Modalidades de intervenção em espaços-tempos de formação: (in)visibilidades e autorias}

$\mathrm{O}$ acesso à informação, ao conhecimento e à aprendizagem tem vindo a ampliar-se significativamente, de tal modo que cada vez mais se reconhece a necessidade e a oportunidade do/no acesso ao conhecimento e à aprendizagem, bem como as potencialidades formadoras não apenas dos espaços-tempos institucionalizados e normativos, mas também dos contextos abertos, não estritamente programados e mais ou menos informais.

Esta ampliação e reconhecimento dos espaços-tempos formadores, convém salientar, opera-se não apenas pela via dos discursos da importância e da necessidade da "aprendizagem ao longo da vida" - que convoca os sujeitos individuais a tornarem-se "sujeitos aprendentes" (DUBAR, 2000), responsabilizando-os nas suas aprendizagens e na rentabilização em competitividade/empregabilidade no mercado do trabalho e do emprego -, mas também pela constatação da (in)visibilidade de aprendizagens particularmente significativas e relevantes produzidas em contextos de (inter)ação (sociais, lúdicos, profissionais...) mais ou menos informais ou não diretamente intencionais enquanto espaços-tempos de formação.

Os desafios que se colocam aos sistemas e metodologias de formação de jovens e adultos deverão ser encarados e articulados com as novas concepções de sociedade e do trabalho, onde se constata a importância das relações e interações na gestão do quotidiano e a necessidade de uma abordagem estratégica global. 
Vários autores (ZARIFIAN, 1992; VELTZ e ZARIFIAN, 1993; ALTER, 1999; SILVA, 2007) constataram, por meio de pesquisas empíricas realizadas, que as qualidades das organizações e das intervenções socioprofissionais dependem mais das qualidades das interações comunicacionais entre os atores do que da eficiência da ação de cada um deles (CORREIA, 1999).

Neste sentido, são interrogadas e postas em causa as lógicas subjacentes às modalidades de formação mais preocupadas com a transmissão de saberes e com a promoção de competências individuais. Devemos, assim, questionar as intervenções formativas pautadas por uma racionalidade meramente cognitiva e instrumental, com freqüência estruturadas numa lógica de condicionamento (PERETTI, 1991) - que serviria ao modelo tecnicista, nomeadamente de trabalho - e fomentar aquelas que possam instituir-se em instâncias de pilotagem de mudanças refletidas e de desenvolvimento de redes de relações densas e diversificadas, contribuindo para o desenvolvimento de capacidades que potenciem a descoberta de soluções originais e oportunas face às situações imprevistas (CORREIA, 1999).

Estas últimas concentram-se na organização da aprendizagem pela iniciativa (PERETTI, 1991), numa lógica construtivista da aprendizagem, em que as componentes da autonomia, participação, interação e reflexão são particularmente valorizadas, assumindo a partilha de experiências, a autoformação e a supervisão como modalidades importantes de desenvolvimento das capacidades que acima referimos.

As soluções científico-técnicas de natureza instrumental para problemas que o não são, ignorando nos processos de formação a dimensão reflexiva sobre os mecanismos psico-socioinstitucionais (MATOS, 1997) que estruturam as representações e identidades dos sujeitos, são manifestamente insuficientes. Tem-se, por isso, considerado cada vez mais a integração dos saberes experienciais nos processos de formação.

Nos adultos, as experiências vividas são um suporte importante da sua aprendizagem, o que tem sido sublinhado por diversos autores. A conceitualização sobre a aprendizagem dos adultos realizada por Mezirow (1990), os trabalhos desenvolvidos por Kolb (1984) e por Schön (1996), relevam e sustentam, precisamente, a importância da prática e da experiência na formação e na aprendizagem, nomeadamente dos adultos.

Por outro lado, têm ganho particular importância as modalidades inscritas na autoformação. Conforme salientam Carré et al (1997), a sua expansão pode ter subjacentes diferentes ordens de razão, nomeadamente: 
i) econômicas: o incentivo associado à produtividade da formação, reduzindo os seus custos;

ii) socioprofissionais e sociotécnicas: nomeadamente a modificação dos sistemas de trabalho que incentivam a responsabilidade, a iniciativa, o sentido da comunicação e do trabalho em equipe;

iii) a procura de práticas de formação inovadoras: colocando em questão os modelos escolarizados, preconcebidos e regulados, e incentivando-se novas modalidades inscritas em formações abertas, flexíveis e individualizadas;

iv) a autonomia como norma social: vivemos atualmente numa cultura da autonomia, cultura subjacente, também, aos discursos da formação-aprendizagem ao longo da vida. $\mathrm{O}$ valor da autonomia tem vindo a enraizar-se progressivamente, de tal modo que "o indivíduo tradicional, submetido aos poderes discricionários das instituições, tornou-se um sujeito social participante ativo, negociador do poder institucional" (DUMAZEDIER, 1993, in: CARRÉ et al, 1997, p. 17).

Estas razões, associadas ao valor formador da experiência e às potencialidades que os espaços não formais e informais têm na produção de aprendizagens importantes, levam a considerar-se como pertinentes outros espaços e tempos formativos para além dos estritamente formais, normativos e escolarizados (SILVA, 2007).

São estes espaços-tempos, que atravessam as trajetórias de vida dos jovens e adultos, que as metodologias de formação centradas nas autobiografias, nas histórias de vida, na experiência e no reconhecimento da organização aprendente (ZARIFIAN, 1992), procuram interrogar, mobilizar e reconstituir considerando o valor dos saberes não formais, invisíveis e não reconhecidos, tanto pelos próprios autores como pelos outros exteriores. Os sujeitos adquirem, nestas modalidades, a centralidade do processo de aprendizagem. Cabem-lhes a atribuição de sentido a uma realidade complexa - a sua própria biografia e a capacidade de a analisarem e integrarem num contexto mais amplo -, mobilizando as suas histórias cognitivas, afetivas e sociais e as suas capacidades para autoproduzirem a própria vida, constituindo-se a si próprios como recursos no processo de formação-aprendizagem (CHARLOT, 1997; SILVA, 2000).

Tomando como referência as virtualidades formadoras que as trajetórias e biografias dos sujeitos têm e as implicações pedagógicas e 
metodológicas no campo da formação, Correia (1998, p. 145) afirma que: "as correntes pedagógicas mais preocupadas com a reabilitação das experiências sugerem que o problema da participação deve ser deslocado da intervenção dos formadores e reequacionado tendo em conta a trajetória de formação dos formandos" e, neste caso, o jovem ou adulto, ao reconhecer-se como sujeito experiente, aprende também a tornar-se pedagogo face às situações que caracterizam a sua vida.

Estas modalidades de formação, para além de deslocarem a intervenção formativa dos formadores para os formandos, investem no desenvolvimento das capacidades reflexivas dos sujeitos, de modo a constituírem-se num recurso essencial para se apropriarem de si próprios, dos seus saberes e da sua ação. Estas capacidades reflexivas internas e intra-subjetivas são acompanhadas pelo desenvolvimento de interações e de partilhas e pelo reconhecimento do potencial intersubjetivo e comunicacional na apropriação das aprendizagens.

A importância atribuída hoje à experiência encontra-se, assim, articulada com a reflexão que os sujeitos são capazes de produzir sobre eles próprios e sobre a sua ação no mundo, sendo, por isso, estruturante do desenvolvimento do adulto na sua globalidade, nomeadamente quando é pensada no contexto de uma reflexividade crítica, geradora de uma consciência contextualizada (NÓVOA e FINGER, 1988). Ao assumir-se a experiência dos jovens e adultos na (sua) aprendizagem, implica que a consideremos como "um processo interno do sujeito e que corresponda, ao longo da sua vida, ao processo da sua autoconstrução como pessoa" (CANÁRIO, 1999, p. 109).

Estas metodologias inserem-se em dispositivos de formação, onde os conteúdos mobilizados emergem da historicidade e singularidade dos indivíduos. São saberes ocultos, que emergem do quotidiano, favorecendo o seu questionamento e (re)elaboração através da escuta e da intercomunicação. Estes últimos ocupam o lugar dos saberes formais, predefinidos e preexistentes à situação de formação, estruturados numa lógica cumulativa de saberes especializados e transferíveis.

Estes dispositivos favorecem um trabalho de formação que valoriza a comunicação e a construção de saberes, sendo que esse trabalho, como salienta Correia (1995, p. 24),

não se limita a proceder a um registro e a uma observação prévia dos saberes experienciais. Para além de se preocupar com o reconhecimento 
destes saberes, procura induzir situações onde os indivíduos se reconheçam nos seus saberes e sejam capazes de incorporar no seu patrimônio experiencial os próprios saberes produzidos pelas experiências de formação. Este reconhecimento dos saberes experienciais não tem, no entanto, apenas uma valência retrospectiva, mas fundamentalmente uma dimensão projectual.

Para finalizarmos, consideramos importante salientar a relevância das trajetórias e experiências individuais e sociais dos jovens e adultos, as quais poderão ser estruturadas e recompostas através das metodologias e dispositivos de formação que antes enunciamos. Assim, os desafios que se colocam à formação de jovens e adultos perspectivam-na face a uma diversidade de modalidades de formação alternativas que incluem desafios igualmente essenciais no modo de pensar e organizar a formação. Esta terá de passar de uma lógica baseada nos modelos escolarizados, tecnicizados e transmissivos, a lógica da previsão e da intervenção dos formadores e das instituições de formação, para uma lógica em que os sujeitos jovens e adultos em formação, as suas vivências e experiências são os pontos de partida essenciais na construção dos dispositivos de formação.

Em síntese, as virtualidades formadoras da(s) experiência(s) na aprendizagem, nomeadamente dos jovens e adultos, decorrem do seu potencial de saberes (invisíveis e profanos) e das suas potencialidades na construção ativa de novos conhecimentos emergentes a partir da reflexão inter e intrasubjetiva, contribuindo para a (re)composição e (re)construção de novos saberes.

A reabilitação dos saberes da experiência implica, por um lado, rupturas com a definição dominante do estatuto epistemológico dos saberes pertinentes para a gestão do incerto, rupturas quanto à definição dos modelos organizacionais que melhor se adequariam às características dos sistemas e às circunstâncias locais (CORREIA, 1998, p. 132) e rupturas, também, com os modelos pedagógicos até agora dominantes no âmbito da formação e, por outro lado, implica uma perspectiva distinta e renovada dos dispositivos de formação, bem como das situações educativas e dos modos de aprender e de formar(-se). 


\section{REFERÊNCIAS}

ALTER, N. La gestion du désordre en entreprise. Paris: L'Harmattan, 1999.

ANDERSON, R.; HUGHES, J.; SHARROCK, W. Philosophy and the Social Sciences. London: Croom Helm, 1986.

BARTH, B.-M. Construire son savoir. In: BOURGEOIS, É. (Édt.), L'adulte en formation . Regards pluriels. Paris : De Boeck, 1996, p.19-36.

BOUTINET, J.-P. L'immaturité de la vie adulte. Paris: PUF, 1998.

CANÁRIO, R. Educação de adultos. Um campo e uma problemática. Lisboa: Educa, 1999.

CARRÉ, Ph.; MOISAN, A.; POISSON, D. L'autoformation. Paris: PUF, 1997.

CHARLOT, B. Du rapport au savoir: éléments pour une théorie. Paris: Anthropos, 1997.

COMISSÃO EUROPÉIA. White paper on education and training-Teaching and learning towards the learning society. (Impresso a partir da Internet), 1996.

CORREIA, J. A. Formação e trabalho: contributos para uma transformação nos modos de os pensar na sua articulação. In: ESTRELA, A. et al. (Eds.). COLLOQUE NATIONAL, 4. Actas (v. 1). Lisboa: AFIRSE Portuguesa, Universidade de Lisboa, 1995, p. 3-30.

CORREIA, J. A. Para uma teoria crítica em educação. Porto: Porto Editora, 1998.

CORREIA, J. A. Os "lugares-comuns” na formação de professores. Porto: Edições ASA, Coleção Cadernos Pedagógicos, 1999.

DUBAR, C. La crise des identités. L'interprétation d'une mutation. Paris: PUF, 2000.

DUBAR, C. ; TRIPIER, P. Sociologie des professions. Paris: Armand Colin, 1998.

HABERMAS, J. Théorie de l'agir communicationnel. Paris: Fayard, 1987.

HOUDE, R. Les transitions de la vie adulte et la formation expérientielle. Éducation Permanente, n. 100/101, 1989, p. 143-150.

KOLB, D. Experiential learning: experience as the source of learning and development. Englewood/cliffs (NJ): Prentice Hall, 1984.

MATOS, M. S. Modelos de profissionalidade docente e modelos de formação. In: ESTRELA, A. et al. (Orgs.). Contributos da investigação científica para a qualidade do ensino. Porto: Sociedade Portuguesa de Ciências da Educação, (Vol. II), 1997, p. 189-199.

MEZIROW, J. Transformative dimensions of adult learning. San Francisco: JosseyBass, 1990. 
NÓVOA, A.; FINGER, M. (Orgs.). O método (auto)biográfico e a formação. Lisboa: Ministério da Saúde, 1988.

PERETTI, A. Organiser des formations. Paris: Hachette, 1991.

PINEAU, G. Produire sa vie: autoformation et autobiographie. Paris: Edilig, 1983.

PINEAU, G. Temporalidades na formação. São Paulo: TRIOM, 2004.

SANTOS, B. S. Da idéia de Universidade à Universidade da idéia. Revista Crítica de Ciências Sociais, Coimbra, n. 27/28, 1989.

SANTOS, B. S. Um discurso sobre as Ciências. Porto: Afrontamento, 1988.

SCHÖN, D. A la recherche d'une nouvelle épistémologie de la pratique et de ce qu'elle implique pour l'éducation des adultes, In: BARBIER, J.-M. (Org.). Savoirs théoriques et savoirs d'action. Paris: PUF, 1996, p.201-222.

SILVA, A. M. C. (Re)Inventar a formação de adultos: controvérsias e desafios. In: MOREIRA, A. F. et al. (Orgs.). Currículo: pensar, sentir, diferir. Rio de Janeiro: DP\&A Editora, 2004, p. 57-76.

SILVA, A. M. C. Da formação de adultos ao adulto em formação. Revista GalegoPortuguesa de Psicologia da Educação, Coruña, n. 4, v. 6, 2000, p. 666-677.

SILVA, A. M. C. Formação: espaço-tempo de mediação na construção de identidade(s). Coimbra: ARIADNE Editora, 2007.

USHER, R.; BRYANT, I. La educación de adultos como teoría, práctica e investigación. El triángulo cautivo. Madrid: Ed. Morata, 1992.

VELTZ, P.; ZARIFIAN, P. Vers de nouveaux modèles d'organisation? Sociologie $d u$ Travail, n. 1/93, 1993, p. 3-5.

ZARIFIAN, Ph. Acquisition et reconnaissance des compétences dans une organisation qualifiante. Éducation Permanente, n. 112, 1992, p. 15-22.

Texto recebido em 15 de nov. 2006 Texto aprovado em 10 de fev. 2007 